\title{
Total Hip Replacement in Inflammatory Hip Disease using the Charnley Prosthesis
}

\author{
JACQUELINE HARRIS, C. D. R. LIGHTOWLER, R. C. TODD
}

British Medical fournal, 1972, 2, 750-752

\section{Summary}

The Charnley low-friction arthroplasty was performed on 73 hips in 55 patients with inflammatory joint disease, usually for intolerable pain. Sixty-five of these operations were reviewed at a special clinic or by postal questionnaire; 57 hips were painfree or gave rise to only occasional discomfort, in 58 there was an increased range of movement, and in 46 of the 59 hips assessed clinically, the results were excellent or good. The most serious complication was deep infection, which occurred in 7 operations.

\section{Introduction}

In patients with inflammatory arthropathy the hip joint is often the site of severe destructive change which causes unacceptable pain, stiffness, and disability. Involvement of this joint is more frequent than is generally appreciated-for example, Glick, Mason, and Wenley ${ }^{1}$ showed that the hip joint was involved in $29 \%$ of cases of patients with rheumatoid arthritis attending the London Hospital. Moreover, involvement of the hip is a critical event leading to important functional deterioration. In the advanced case surgery offers the only hope of relief, the problem hitherto being to find a satisfactory procedure.

With the development of total hip replacement ${ }^{2-4}$ the possibility of substantial relief of symptoms has become practicable. The Charnley low-friction arthroplasty has proved to be an

London Hospital, London E.1

JACQUELINE HARRIS, M.R.C.P., Senior Registrar in Rheumatology

C. D. R. LIGHTOWLER, F.R.C.S., Senior Registrar in Orthopaedic (Present appointment: Consultant Orthopaedic Surgeon, South Essex Group of Hospitals)

R. C. TODD, F.R.C.S., Senior Registrar in Orthopaedics extremely successful procedure when performed in the highly specialized unit at Wrightington. ${ }^{5}$ Demand for the operation is so great, however, that an increasing number of orthopaedic surgeons want to perform total hip replacements. It therefore seemed appropriate to review the results of this operation after four and a half years' experience in the busy general orthopaedic unit at the London Hospital.

\section{Material and Methods}

The main indication for low-friction arthroplasty was intolerable pain in a joint which was the site of severe destructive change. In two cases surgery was undertaken because of severe limitation of movement in the hip with resulting disability.

From August 1966 to December 197073 Charnley total hip replacements were performed on 55 patients with inflammatory arthropathies (Table I). Eighteen of the patients with rheumatoid

TABLE I-Diagnoses and Number of Operative Procedures

\begin{tabular}{|c|c|c|c|c|}
\hline \multicolumn{2}{|l|}{ Diagnosis } & $\begin{array}{c}\text { No. of } \\
\text { Patients }\end{array}$ & $\begin{array}{l}\text { No. with } \\
\text { Bilateral Operations }\end{array}$ & $\begin{array}{l}\text { No. of } \\
\text { Hips }\end{array}$ \\
\hline 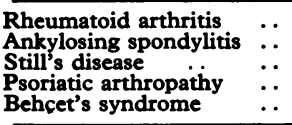 & $\begin{array}{l}\cdots \\
\because \\
\cdots\end{array}$ & $\begin{array}{r}41 \\
9 \\
2 \\
2 \\
1\end{array}$ & $\begin{array}{r}13 \\
3 \\
1 \\
1 \\
0\end{array}$ & $\begin{array}{r}54 \\
12 \\
3 \\
3 \\
1\end{array}$ \\
\hline Total & .. & 55 & 18 & 73 \\
\hline
\end{tabular}

arthritis were being treated with corticosteroids and 29 had suffered from the disease for over 10 years. In five instances the operated hip was the site of previous surgery (three cup arthroplasties, one Moore prosthesis, and one pin and plate for fracture). Seven patients with ankylosing spondylitis had previously had cup arthroplasties on the operated hip. (The patient with Behçet's syndrome developed an aseptic necrosis of the 
femoral head attributed to corticosteroid therapy prescribed for uveitis.)

The ages of the patients at operation are shown in Table II.

Seventy hips were operated upon by means of the Charnley technique ${ }^{b}$ - a lateral incision is made and the greater trochanter is removed with muscles attached. Three hips were approached by the anterior Smith-Peterson method. The general management of the patients was the same as that described in the accompanying paper. ${ }^{7}$

TABLE II-Age at Operation

\begin{tabular}{ll|c|c|c|c|c|c|c|c}
\hline Age in years &. & $<20$ & $20-29$ & $30-39$ & $40-49$ & $50-59$ & $60-69$ & $70-79$ & $\geqslant 80$ \\
No. of patients &.. & 1 & 2 & 4 & 12 & 15 & 15 & 5 & 1 \\
\hline
\end{tabular}

\section{Results}

Forty-four patients were reviewed in a special follow-up clinic and five replied to a questionnaire. Three patients had died and three were lost to follow-up. Thus $94 \%$ of patients who were still alive were assessed. This represents 59 hips seen at followup and 6 assessed by questionnaire-a total of 65 operations. The duration of follow-up is shown in Table III.

TABLE III-Time since Operation in the 49 Patients available for Follow-up

\begin{tabular}{lll|l|l|l|l|l}
\hline $\begin{array}{l}\text { Time in years } \\
\text { No. of operated hips }\end{array}$ & $\ldots$ & $\ldots$ & $3 / 12-1$ & -2 & -3 & -4 & -5 \\
\hline
\end{tabular}

Pain Relief.-Ninety-five per cent. of the hips were severely painful before total hip replacement, but postoperatively 57 $(88 \%)$ were pain-free or gave only occasional discomfort. Four hips $(6 \%)$ were still painful after operation-in one instance this was due to infection, in one to a poor technical procedure, and in two there was no obvious cause for the pain. Four prostheses were removed because of infection.

Passive Range of Movement.-This assessment was made on 55 hips of patients who attended for follow-up (excluding four patients in whom the prosthesis had been removed). The sum

TABLE IV-Range of Hip Movement before and after Operation

\begin{tabular}{ll|l|l|l|l|l|l|l}
\hline & Grade: & 1 & 2 & 3 & 4 & 5 & 6 \\
\hline $\begin{array}{l}\text { No. of hips preoperatively } \\
\text { No. of hips postoperatively }\end{array}$ & $\cdots$ & 7 & 10 & 19 & 13 & 3 & 3 \\
\end{tabular}

Postoperative flexion was $90 \%$ or more in 19 .patients, $60-90 \%$ in 30 , and $30-60 \%$ in 6.

of flexion, abduction, adduction, and internal and external rotation was calculated before and after operation and then expressed as a grade according to the method of d'Aubigne and Postel $^{8}\left(0-29^{\circ}=1,30-59^{\circ}=2,60-99^{\circ}=3,100-159^{\circ}=4\right.$, $160-209^{\circ}=5,210-260^{\circ}=6$ ). The results are given in Table IV. The patients who replied to a questionnaire all said that movement in the hip had increased since operation. If we accept this there was increased movement postoperatively in $89 \%$ of hips.

Complications.-The complications of this operation are recorded in Table V. By far the most serious was deep infection, which occurred in seven instances $(10.8 \%)$. Two patients with ankylosing spondylitis who had had previous cup arthroplasties performed on the operated hip developed deep infections. In one this occurred early and Staphylococcus aureus was cultured; in the other infection developed at nine months and no organism was grown (treatment with antibiotics had been started before the wound discharged and a swab could be taken). One of the patients with rheumatoid arthritis who had an early superficial
TABLE v-Complications of the Operation

\begin{tabular}{|c|c|c|c|c|}
\hline Complication & & $\begin{array}{l}\text { Rheumatoid } \\
\text { Arthritis }\end{array}$ & $\begin{array}{l}\text { Ankylosing } \\
\text { Spondylitis }\end{array}$ & Others \\
\hline $\begin{array}{l}\text { Superficial vein thrombosis } \\
\text { Deep vein thrombosis } \\
\text { Pulmonary embolism } \\
\text { Wound haematomata . }\end{array}$ & $\begin{array}{l}\because \\
\because \\
\because \\
\because \\
\because \\
\because\end{array}$ & $\begin{array}{l}2 \\
4 \\
1 \\
3 \\
3 \\
5 \\
2 \\
1 \\
3\end{array}$ & $\begin{array}{l}0 \\
3 \\
1 \\
0 \\
0 \\
2 \\
0 \\
1 \\
1\end{array}$ & $\begin{array}{l}\mathbf{0} \\
0 \\
0 \\
0 \\
1 \\
0 \\
0 \\
0 \\
1\end{array}$ \\
\hline
\end{tabular}

wound infection subsequently developed a deep infection at five months. The wound was sterile initially and then Pseudomonas and Proteus were cultured. A further two patients (both being treated with corticosteroids) developed sterile discharging sinuses at 33 and 36 months respectively. In two other cases infection with Staph. aureus followed open reduction of a dislocated prosthesis. All patients who developed deep infections were treated with antibiotics for various reasons during the postoperative period. In four of these patients the prosthesis was removed, leaving a Girdlestone pseudarthrosis, and one patient awaits removal. The other two were not fit enough for further surgery.

Clinical Assessments. - We have used a modification of the method suggested by Arden, Taylor, and Ansell ${ }^{\circ}$ to assess the results of the operation. Thus an excellent result indicates $90^{\circ}$ or more of flexion with no pain, good at least $90^{\circ}$ of flexion with occasional discomfort or $60-89^{\circ}$ with no pain or occasional discomfort, fair $30-59^{\circ}$ of flexion with no pain or occasional discomfort, and poor the remainder. Of the 59 hips assessed clinically the result was excellent or good in 46 (78\%) (Table VI). Eighty-five per cent. of the operations were classified by the patients as excellent or good. There was no tendency for poor results to be related to increased duration of follow-up.

TABLE vi-Overall Assessment of the 59 Hips assessed Clinically

\begin{tabular}{|c|c|c|c|c|c|}
\hline Disease & & Excellent & Good & Fair & Poor \\
\hline $\begin{array}{ll}\text { Rheumatoid arthritis } & \ldots \\
\text { Ankylosing spondylitis } & \ldots \\
\text { Still's disease } & \ldots \\
\text { Psoriatic arthropathy } & \ldots \\
\text { Behçet's syndrome } & \ldots\end{array}$ & $\begin{array}{l}\cdots \\
\cdots \\
\cdots\end{array}$ & $\begin{array}{r}10 \\
3 \\
0 \\
2 \\
0\end{array}$ & $\begin{array}{r}22 \\
4 \\
3 \\
1 \\
1\end{array}$ & $\begin{array}{l}2 \\
0 \\
0 \\
0 \\
0\end{array}$ & $\begin{array}{l}9 \\
2 \\
0 \\
0 \\
0\end{array}$ \\
\hline Total & . & $15(25 \%)$ & $31(53 \%)$ & $2(3 \%)$ & $11(19 \%)$ \\
\hline
\end{tabular}

\section{Discussion}

It is now nearly five years since the Charnley low-friction arthroplasty was first performed at the London Hospital. Initially only patients aged 65 or over were treated, but the early results were so encouraging that this operation is now considered in any age group if there is hip disease causing intolerable pain or severe limitation of movement with resulting disability. It seems clear from our experience that if the patient is fit for the anaesthetic total hip replacement can be considered despite steroid therapy, severe joint destruction, or osteoporosis.

Our results are less favourable than those of Welch and Charnley, ${ }^{5}$ who obtained pain relief in $94.7 \%$ of 307 operations for inflammatory joint disease and an increase in range of movement in $98.6 \%$. The present operations, however, were performed in a routine orthopaedic setting by many surgeons, including those in training. It is a tribute to this procedure that successful results can be achieved outside specialized centres such as the Centre for Hip Surgery, Wrightington. Provided the operation is well done sepsis is the only serious problem.

The incidence of deep infection in this series $(10.8 \%)$ is a cause for grave concern. The reasons for this high rate of infec- 
tion have been discussed in the accompanying paper, ${ }^{7}$ in which there were $5.3 \%$ of deep infections in 352 operations for osteoarthrosis of the hip. Arden et al., ${ }^{9}$ using the McKee-Farrar prosthesis, also found an increased incidence of deep infection in rheumatoid arthritis $(7 \cdot 1 \%$ ) compared with $2.2 \%$ in osteoarthrosis. In Welch and Charnley's ${ }^{5}$ series the incidence of deep infection was appreciably lower, being $0.7 \%$ in 307 operations for rheumatoid arthritis and ankylosing spondylitis. The orthopaedic operating theatre at this hospital is being equipped with sterile laminar airflow, and it is hoped that this will reduce the number of infections.

We are indebted to Sir Henry Osmond-Clarke, Mr. O. J. Vaughan-Jackson, Mr. W. A. Law, and Mr. M. A. R. Freeman for allowing us to review patients under their care. We should like to thank Mr. M. A. R. Freeman and Dr. Michael Mason for their help in preparing this paper, and Miss J. M. Piercy, Miss D.
Hayes, Mrs. P. Young, and Mrs. A. S. McKee for their help in assessing the patients.

\section{References}

1 Glick, E. N., Mason, R. M., and Wenley, W. G., Annals of the Rheumatic Diseases, 1963, 22, 416.

3cKee, G. K., and Watson-Farrar, J., fournal of Bone and foint Surgery, 1966, 48B, 245 .

1966, 48B, 245.
Ring, P. A., fournal of Bone and foint Surgery 1968, 50B, 720.

: Ring, P. A., fournal of Bone and foint Surgery 1968, 50B, 720. 1970, 72, 22.

- Charnley, J., Clinical Orthopaedics and Related Research, 1970, $72,7$.

Todd, R. C., Lightowler, C. D. R., and Harris, J., British Medical fournal, $1972,2,752$.

8 D'Aubigne, R. M., and Postel, M., fournal of Bone and foint Surgery, 1954, 36A, 451 .

- Arden, G. P., Taylor, A. R., and Ansell, B. M., Annals of the Rheumatic Diseases, 1970, 29, 1.

\title{
Total Hip Replacement in Osteoarthrosis using the Charnley Prosthesis
}

\author{
R. C. TODD, C. D. R. LIGHTOWLER, JACQUELINE HARRIS
}

British Medical fournal, 1972, 2, 752-755

\section{Summary}

Charnley low-friction arthroplasty was performed on 352 osteoarthritic hips, usually because of severe pain. Three hundred and twenty hips were reviewed at a special follow-up clinic or by postal questionnaire. After operation $89 \%$ of hips were pain-free or caused only occasional discomfort, and in $\mathbf{7 6} \%$ there was an increased range of movement. Of those patients actually seen for review $79 \%$ were judged to have a good or excellent result. The most frequent single complication was deep infection, which occurred in $5 \cdot 3 \%$ of hips.

\section{Introduction}

Osteoarthrosis of the hip is an important cause of pain and disability, and its treatment forms a large proportion of the work in any general orthopaedic unit. With an increasingly elderly population this problem is likely to become even more important. ${ }^{1}$ Undoubtedly total hip replacement can produce extremely good results, especially when performed in a special centre. This review reports the results of one type of total hip replacement-Charnley low-friction arthroplasty-performed over a period of four and a half years in a busy general orthopaedic unit.

\section{Material and Methods}

Between August 1966 and December 1970352 Charnley lowfriction arthroplasties were performed at the London Hospital for osteoarthrosis. During that time this was, with only one or two exceptions, the only form of total hip replacement used in the unit.

London Hospital, London E.1

R. C. TODD, F.R.C.S., Senior Registrar in Orthopaedics

C. D. R. LIGHTOWLER, F.R.c.s., Senior Registrar in Orthopaedics (Present appointment: Consultant Orthopaedic Surgeon, South Essex Group of Hospitals)

JACQUELINE HARRIS, M.R.C.P., Senior Registrar in Rheumatology
The indications for operation were severe pain disturbing sleep or preventing normal activities or, less commonly, stiffness of the hip with, in each case, radiological changes of advanced osteoarthrosis. Initially the operation was performed only on patients over 65 years of age or on younger patients with "builtin brakes," but later this age limit was somewhat relaxed. The operations were performed by surgeons of varying degrees of experience (four consultants and 10 of their senior registrars or registrars). They were carried out on routine operating lists with none of the extra precautions against infection found at the Centre for Hip Surgery, Wrightington.

Eight hips were approached through an anterior SmithPeterson incision, but in the remainder (344) the standard Charnley technique ${ }^{2}$ was used-that is, a lateral approach and detachment of the trochanter. Postoperatively the patients were kept in bed with the legs abducted for seven days and were then mobilized with walking aids which were discarded when confidence and walking ability allowed. One consultant preferred patients under his care to use elbow crutches for six weeks to reduce the strain on the greater trochanter while it was uniting. There was no regular policy regarding the use of antibiotics, either systemic or local. A large proportion of patients received a course of ampicillin and cloxacillin, starting with the premedication and continuing for several days. Others received antibiotics in the postoperative period for chest or urinary infections. A few patients included in this review took oxytetracycline for 3-14 days preoperatively when a pathological study was being made of the osteoarthritic femoral head.

Of the 308 patients treated ( 90 men, 218 women) 44 had bilateral operations. The ages of the patients at operation are shown in Table I. Previous operations had been performed on 111 hips, as shown in Table II.

TABLE I-Age at Operation

\begin{tabular}{ll|c|c|c|c|c|c|c}
\hline Age in years &.. & $20-29$ & $30-39$ & $40-49$ & $50-59$ & $60-69$ & $70-79$ & $\geqslant 80$ \\
No. of patients &.. & 1 & 3 & 8 & 70 & 140 & 74 & 12 \\
\hline
\end{tabular}

TABLE II-Previous Operations on 111 Hips

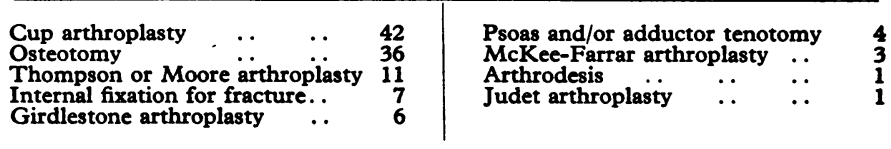

